\title{
Cultural and religious perspective of loss and bereavement in Anatolia
}

\author{
Fuat Tanhan ${ }^{1}$ \\ Süleyman Kasap ${ }^{2}$ \\ Firat Ünsal ${ }^{3}$
}

\begin{abstract}
Coping with death is a grueling job to be done however it is not impossible. All cultures have developed ways to cope with death. Interfering with these practices may interfere with the necessary grieving processes. Understanding different cultures' and religions response to death can help counselors recognize the grieving process in patients of other cultures. It is also important to realize that, while each individual grief process is unique, there is a form of grief that is disabling, interfering with function and quality of life. A great majority of the people in Anatolia have remained under the influence of tradition as well as religion. In the foundation of main behavior models which forms our traditional life, ensuring them to possess specialty and formation however there lays numerous customs, beliefs and ethic operations. So that such kind of variations affects the death and the bereavement customs. As in the case of the three important event of the life, a great number of beliefs, customs, tradition, ceremonies, and behaviors have been also grouped around death. Such beliefs, customs, transactions, ceremonies and pattern behaviors which accumulated around the death and surrounded individuals with the death are collected under three groups. Sets of traditions formed as pre-death, during death and after death. So this study was carried out so as to determine the approach of Anatolian traditions to the death and bereavement. This qualitative research was conducted by means of semi-structured interviews in which three questions prepared by the researchers and were asked to four volunteer male participants whose mean age was seventy-five years old. The study concludes that the traditions of Anatolia give importance to sharing and supporting the family of deceased, which overlaps the literature of bereavement process psychology.
\end{abstract}

Keywords: Anatolia; Culture; Loss; Death; Bereavement.

\section{Introduction}

Death is undoubtedly one of the most universal and ancient themes, always arousing wide variety of emotions and attitudes, and is generally regarded as a misfortune, evil, and the fear and anxiety (Kastenbaum; Aisenberg, 1983). It may take months or even years for some bereaved individuals to make sense of their loss, find meaning in it, and mature from the experience. (Schaefer \& Moos, 2001). Initially the griever experiences a strong desire to maintain ties to the deceased. Unwilling to abandon the lost object, the mourner repeatedly tests the reality of the loss by seeking to include the individual as part of his or her ongoing life structure (Russac, Steighner \& Canto, 2002). When, grief starts, which can be defined as 'a deep sadness', a 'kind of pain inside a person', a 'sense of

\footnotetext{
${ }^{1}$ Assoc. Prof. Dr., Yuzuncu Yil University, Education Faculty, Department of Education Sciences, fuad65@gmail.com

${ }^{2}$ Dr., Ministry of Education, , kasap hakanl@hotmail.com

${ }^{3}$ M.D., Ministry of Education, brukani@gmail.com
} 
Tanhan, F., Kasap, S., \& Ünsal, F. (2016). Cultural and religious perspective of loss and bereavement in Anatolia. Journal of Human Sciences, 13(3), 4181-4187. doi:10.14687/jhs.v13i3.3892

something missing', 'a hopelessness' and a 'helplessness' " (Cowles, 1996). ccording to Vale-Taylor, 2009 the experience of suffering and loss may have an adverse effect on the proper functioning of the immune system, accentuating the risk of disease and possibly hastening death. Examples of current problems in people who have lost someone dear to them was also noted the increase in alcohol consumption, drugs, the onset of depressive disorders and the inability to work.

All cultures have developed ways to overcome grief and the fear of death. Understanding different cultures and religions' response to death can help counselors recognize the grieving process in patients of other cultures. Nevertheless, the more we are making advancements in science, the more we seem to fear and deny the reality of death and we just want it occurs away from home, away from family, meaning in hospitals. (Brayne; Fenwick, 2008). The place where one dies today is different from the old days in that old generations used to die at home, and could have the chance of saying goodbye to the family, thus solving the last commitments their lives. Everyone around could witness that sad event and accept this event as natural phenomenon. However, currently, and since the 60s of the last century, progress in the field of resuscitation and intensive care doctor led to the hospitalization of death. In some countries, these changes were so evident that today, two thirds of British people die in hospitals and $80 \%$ of deaths in the United States occur in various health institutions (Nuland, 1994). his social transformation has led to a gradual disappearance of it in community context. Actually most of are not willing to be exposed to death since it cause us to be unhappy and hopeless. Materialism and hedonism cannot stand the thought of death because it will upset a growing consumerism of goods and pleasures; therefore, death is seen as a purely biological fact and not as a profound human reality (Barros de Oliveira, 1998). Since talking about death is not a romantic or attractive topic, people generally tend to ignore or avoid speaking about it. It can be said that there is a denial of death in societies in which death is viewed as a taboo (Kübler-Ross,1969). his denial, though natural, may or may not be reinforced by the cultural system, which might have a role in death education. Because one the main goals of death education is to teach individuals how to overcome grief and ceremonies with friends and relatives serve to help us through our experiences and give us security. Others help us by expressing their sympathy and concern. They show us that we are still loved and appreciated (Noppe , 2004). In Anatolia, friends visit the house of the deceased and talk with the family members, encouraging them to describe how the death occurred, what they were doing at the time of death and so forth. For seven days, the family members are never left alone. Friends and neighbors bring food, as no cooking is supposed to be done in a funeral home during those seven days. Traditionally, no television, radio or any musical devices would be allowed for 40 days but this practice has waned in recent years. Mourning period in Anatolia varies from three days to years, depending on the manner of death of the person, his /her social status, his/her being male or female, being old or young can take years, beginning three days (Ornek,1979). Black is a common color which is chosen for the mourning clothes among Anatolian people. The removal of mourning can be related to the removing of mourning clothes, instead of which white colors are worn as sign of turning to the normal life. The pain of the people is shared by the relatives and neighbors of deceased person and family of deceased house are never left alone. For instance the, in Gaziantep - a province in Turkey- neighbors don't go on for holidays or perform weddings ceremonies when somebody die in their neighborhood and they wait for the mourning period to end (Guzelbey, 1975) . In some cities in eastern cities of Turkey such as Sanliurfa, Erzincan, after a week or ten days after the death of her dead the neighbors of relatives of the deceased are taken to the bath houses in order to end the process of mourning (Sezen, 1993). The neighboring women come and clean the house the bereaved as a sign of fresh start.

In Van province of Turkey, men of the mourning house do not shave for about one week or a month and they are taken to barber to be shaved and so that they can keep on their normal lives. However, it does not mean forgetting about deceased person at all, for there is a religious prayer at 
Tanhan, F., Kasap, S., \& Ünsal, F. (2016). Cultural and religious perspective of loss and bereavement in Anatolia. Journal of Human Sciences, 13(3), 4181-4187. doi:10.14687/jhs.v13i3.3892

the 40th and another at the 52nd day after the death of that person so as to commemorate him or her (Tan, 1965).

The purpose of present study is to discuss the death rituals of Anatolia with relation of religion and cultural perspectives by taking death education literature into account, thereby gathering data by means of semi-structured interviews with senior participants in a particular region.

\section{Methodolog}

This qualitative research was conducted in 2016, March by means of semi-structured interview which is commonly used in qualitative research (Edwards; Holland, 2013). In this study, three questions prepared by the researchers were asked to four volunteer male participants from Van Province in Turkey and whose mean age was seventy-five years old. Finally the interviews were recorded and analyzed by the researchers. Three semi-structured interview questions were conducted qualitatively to get information about the customs of Anatolia related to death. The first one was related to pre-death, the second one was asking about during death and the last one was demanding information about customs of the region after death. The semi-structured interview was open so that the researchers could get new ideas and information during the interview in accordance with what the interviewees told.

\section{Questions}

Three main questions asked were;

- If death is imminent, what do you do in terms of your customs, traditions and religion (Pre- Death)?

- According to your culture, what do you do after a person dies (During Death)?

- Do you have any traditional or religious requirements after the deceased being buried (After Death)?

\section{Pre-Death}

The question dealt with the interviewees' customs, traditions and religious requirements when death is imminent gave insight into the fact that if they think the person will die soon, the first thing they are required to do is to call an Imam (Hodja) or a person who can read Qur'an loudly -this generally is done by that person's close relatives- and if dying person is a female, a woman or close male relative reads Qur'an. Because they believe that the verses of Qur'an comfort the person and diminish the fear of death. Then the close relatives of that person are called to visit him/or her for the last time and say good bye. If one of the relatives does not come, it is believed that dying person passes away with open eyes. The people there generally tell their loved one show much they care about, pray for them and then they forgive them so that Allah may forgive him/her as well. According to Byock ,2014, dying people want to hear four very specific messages from their close relative "Please forgive me." "I forgive you." "Thank you." "I love you."

Giving Zamzam water, which is believed to be sacred, to dying person is also thought to ease to suffer of death. This water is believed to be a miraculously created source of water by Allah, when Abraham's son Ishmael, who was a by then, got thirsty and kept crying because of thirst. Because of the belief, thousands and thousands of pilgrims go to the well of Zamzam and while performing pilgrimages drink its water, they bring this water to their houses and they keep some of it in case somebody dies in their families.

One the most important requirements are that dying person is able to utter Kelime-i Shahada. The person is urged to say Kelime-i Shahada which is Islamic testimony of faith since it is believed that 
if someone says that expression, he or she will go to heaven eventually. Therefore, the close relatives present ought to offer the dying person hope and kindness, and encourage the dying person to say the "shahada," confirming that there is no God but Allah , and if he or she is unconscious, somebody whispers this testimony in his/her ears.

\section{During Death}

The second question of the study was related the customs and religious requirements of the culture and the interviewees have stated that close relatives of the deceased come and see him or her again for the last farewell and crying is accepted very natural and even they are encored to cry for their deceased, which runs parallel with literature because whenever somebody undergo some intense emotional distress like the death of somebody close, his / her body start release some powerful painkilling chemicals which are similar to heroin or morphine, so tears are needed to send these chemicals in the body; however If people want to cry but are prevented, it's possible they are denied some of these natural painkillers that would otherwise help moderate their distress (McKissock, 2011).

After this farewell, the body is taken to a mosque where it must be washed and shrouded. The washing and shrouding of the deceased is an obligation for all Muslims in that community. Even so, if it is done by a group of people in that community, the other members are thought to clear of this requirement. Generally religious Muslim people buy their own shroud after a certain age, if not, shroud is provided by the deceased's relatives. The person who is going to wash and shroud the deceased is generally the one chosen by the deceased himself / herself, if not chosen, The person has to be at the age of legal majority and who is honest, trustworthy, religious, well acquainted with the rules for washing the deceased in accordance with the practices of Prophet Muhammad (saws), and who will not say anything bad about the body of the deceased. The male deceased are washed by men and female ones by women. Death is not the end of a person's existence. Instead, it is a journey to the eternal life ; that's why, people pray for Allah's mercy to be with the deceased and hoping that they may find peace and happiness in heaven. (Zamahsari, 1947).

That belief helps the relatives of the deceased to bear the pain of the loss. According to Islam religion, the body should be buried as soon as possible, which means that funeral planning and preparations should begin immediately. A local Islamic community is announced by the Sala , announcement that gives the news about the identity of the deceased, whereby the person's name and his father's or mother's name announced so that everybody can hear and help the family of deceased.

After Sala, Salat al-Janazah is supposed to be recited, which is a pray performed for the sake of the salvation of the deceased's soul, and the body is to be transported to the cemetery for burial in a coffin. The body of deceased is carried on shoulders of the relatives, friends and neighbors and traditionally, only men are permitted to be present at the burial. The grave, according to the rules of Islam, has to be dug perpendicular to the direction of the Qiblah, to which Muslims turn and perform their prayers, and the body ought to be placed in the grave on its right side, facing the Qiblah. Those placing the body into the grave pray for the soul of the body. After putting the body into the grave, a layer of wood or stones are placed on top of the body to prevent the body being dug out by wild animals. Then the relatives and friends of the deceased place three shovels or handfuls of soil into the grave, which means that "I forgive you and may Allah forgive you as well." When the grave has been filled with earth, a stone or marker is placed at the grave in order that it can be recognizable. Nevertheless, it is not advisable to erect a large monument on the grave or decorate the grave in an elaborate way. Since being humble and not ostentatious is one of the 
main principles of Islam.

Then, a ritual called Telkin (teaching or reminding) is performed after burial. This ritual is led by the imam and he reminds him/her the basic information related to Islam (Allah, Prophet and Holly Book) because it is believed that soul comes back to the soul and the person has to give an account of his deeds while he was alive. If individual passes this test, that person will be in heaven forever. From the perspective of Islamic theology, the questioning in the body is directly to the issue of justice as an attribute of the divine (Dalkilic, 2004) and If the deceased has debt, then the debt must be paid, before being buried or immediately after the burial process. During burial of the body, imam recites prayers aloud in Arabic. Moreover, a certain amount of money is given to the poor to make up for his or her prayers not having been performed and promises not being kept by the deceased when he was alive cannot keep fasts.

\section{After Death}

After the burial process ends, everyone heads for the deceased and his/her children's home and condolence starts there. Condolence generally lasts at least three days. The relatives of the deceased and nearly people in that community are expected to come and read the Surah Fatiha for the comfort of the deceased person's soul. The goal of this ritual is to let the relatives of the deceased person know you're thinking about them, and that they have your support and sympathy. The relatives, friends and neighbors cook and serve food to the people coming to the house of condolence. After three days, the close male relatives of the deceased person (sons, brothers or father) were taken to hair dresser and they were encourage to shave as a sign of turning to normal life, thereby finishing the condolence process and grief. In Turkey, there are certain occasions in which dead person is commemorated through religious ceremony and meal (Unal 1996). First of all is the third day ceremony, death halwa, seventh day ceremony, the fourth day ceremony, the fiftysecond day ceremony and anniversary of dead person. (Aladag, 2016) According to popular understandings the soul of deceased visits home until the corpse is buried, or in forty days after the death or on holy days and in holy months. According to the belief, the soul asks for Dua for itself. Additionally, the grave of the deceased is visited regularly about 10 days more and 41 days after the death of the person her/his family pray organize a gathering called mevlid and mainly relatives come together and read Quran and pray for the soul of the deceased. The first religious festival (Qurban or Ramadan) is called Black Festival for the family of the deceased and the relatives, friends and neighbors visit this family first and they pay a visit to the grave and pray for his or her soul. After this process, mourning returns to normal. Every Holly Day (Eid) the family goes to the grave(s) of their relatives and prays their deceased. For survivors, the creation of such memorials provides not only a focus for physically working through grief, but also a means of perpetuating the memory of the loved one (Despelder, 2008).

\section{Discussion}

Islam views death as a natural passage to the next stage of existence (Mufti, 2015), and the study shows this faith affects the most rituals stated by the participants. The dead has a kind of continued and conscious existence in the grave. The participants believe that at death a person enters an intermediate phase of life between death and resurrection, which comforts the person in deathbed and the close relative of that person. Because literature shows that there is an association of death anxiety to pain, cruelty, loneliness, abandonment if death is regarded as annihilation, absence, loss, abandonment, separation, which will cause pain and fear as the predominant feelings 
in relationship with death (Jaramillo, 2006). Cultural and religious practices applied while the person in his/her deathbed, during and after his/her death apparently have a positive and comforting effect on family and friends of deceased. Such practices as funeral rites aim to contribute to the adjustment, adaptation of not only the deceased but also the those in grief. Beliefs, practices, funeral rites differ between cultures, social groups, yet all are related to the emotions expressed in the face of death are not only individually and collectively depending on the society and its cultural -religious customs (Kubler- Ross ,1969).

The study shows that the participants are aware of every stage of death process and their society has developed rites to cope with the pre-death, during death and after death course. Aforementioned religious and cultural traditions practiced by family members, friends and neighbors of the deceased have positive impacts on that particular community, and that is an important step in death education which is supported by scholars like Kovács (2003) who states that the difficulties and suffering involving a death situations are common to almost all families, but know how to react to changes, challenges, learning, adaptation is unique to each individual and family and it will depend on the history of each of the personality characteristics and also personal and communal effort to address these issues.

\section{Conclusion}

Anatolian people believe that all suffering, life, death, joy and happiness pre-death, during death and after death are derived from God and that God is the one who gives us strength to survive and he is the source of life and death. Death is not an end but a new beginning. These believe are usually sources of comfort and strength that aid the healing process. According to the literature, the social support given by the community can be seen worthwhile. Since sharing your loss and sorrows makes the burden of grief easier to carry, accordingly, the traditions of Anatolia give importance to sharing and supporting the family of deceased. Connecting to others will help the people to heal from the process of the grief.

The study also shows that death ceremony is an important custom closely related to religion and thereby having a deep influence on the traditions of the Anatolian people. The faith and hope that the deceased will go to heaven if prayed for his / her soul also ease the sorrow of family of deceased person. Suppressing one's grief is not advisable (Worden, 1991) and in this culture, we can see that the family is encouraged to cry and show their feelings. Experts also advise that talking about one's loss, memories, and experience of the life and death of the loved one (Wolfelt, 2014). In Anatolian culture talking about the death of the deceased and the memories shared with him/ her is encouraged. The study concludes that cultural and religious traditions of Anatolian people run parallel with the literature regarding with the ways to cope with grieving which is accepted as a personal and highly individual experience.

\section{Conflict of interest}

The authors declared no potential conflicts of interest with respect to the research, authorship, and/or publication of this article. 
Tanhan, F., Kasap, S., \& Ünsal, F. (2016). Cultural and religious perspective of loss and bereavement in Anatolia. Journal of Human Sciences, 13(3), 4181-4187. doi:10.14687/jhs.v13i3.3892

\section{References}

Aladag Municipal, (2016) The Customs in the Aladag Town, http://www.aladag.bel.tr/asp/sosyal.asp

Barros de Oliveira, J. H. (1998). Optimism: Theory and evaluation (proposal for a new scale). Psychology, Education and Culture, 2 (2), 295-308.

Brayne, S.; Fenwick, P.(2008) The art of Dying Continuum Books www.continuumbooks.com

Byock, I. (2014). The Four Things That Matter Most, Atria Books, New York

Corr, C. A. (2013). Death \& Dying Life \& Living. Wadsworth publishing

Cowles, K. (1996). Cultural perspectives of grief: An expanded concept analysis. Journal of Advanced Nursing, 23(2), 287-294.

DeSpelder (2008). The Last Dance: Encountering Death \& Dying, McGraw-Hill Humanities, Social Sciences, Languages, Health \& Human Performance http://webcache.googleusercontent.com

Edwards, R; Holland, J (2013). What is qualitative interviewing? Bloomsbury Academic.

Guzelbey , C. C. (1975) Olum ve Yas Gelenekleri: Gaziantep"te Olum Adetleri. Turk Folklor Arastirmalar1. Vol. 16, no. 316: 7475-7486 is

Jaramillo, I. F.(2006) Learning to live with the absence of the other. Sao Paulo: Brazil Planet, https: //www.reading.ac.uk/apd/research/apd-publications.aspx

Kastenbaum, R.; Aisenberg, R. (1983) Psychology of Death. Sao Paulo: Pioneering

Kovacs MJ (2003) Education for Death: challenge in training bealth and education professionals. Sao Paulo, House Psicologo.

Kubler-Ross,E. (1969) On Death and Dying ,New York: Macmillan

McKissock, M (2011). ABC Health \& Wellbeing, http://www.abc.net.au/health/talkinghealth/factbuster/stories/2011/11/23/3367178.htm

Mufti, K. (2015) Belief Life After Death, The religion of Islam. http://www.islamreligion.com/articles/38/belief-in-life-after-death

Noppe, l. C (2004) Death Education and the Scholarship of Teaching: A Meta-Educational Experience an International, Interdisciplinary Organization, Volume 30, Issue 1

Nuland, S. (1994) How We Die, (New York: Knopf, 1994), Acknowledgment

Ornek, V. S. (1979.), Anadolu Folklorunda Olïm, A..U., DTCF Yay: 218, DTCF Basımevi, Ankara

Russac, R. J., Steighner, N. S., \& Canto, A. (2002). Grief work versus continuing bonds: A call for paradigm integration or replacement? Death Studies, 26, 463-478.

Schaefer, J. A., \& Moos, R. H. (2001). Bereavement experiences and personal growth. In M. S. Stroebe, R. O. Hansson, W. Stroebe, \& H. Schut (Eds.), Hand- book of bereavement research: Consequences, coping, and care (pp. 145-167). Washington, DC: American Psychological Association.

Tan, N. K. (1965) Karahan'da Ölü Gömme ve Yas Tutma, TFA, , Istanbul.

Sezen, L. (1993), Erzurum S,ehir Folkloru, Basilmamıs, Doktora Tezi, A.U. Sosyal Bilimler Enstitüsü, Erzurum,

Unal, M. (1996). A Comparative Study of Funeral Customs in Turkey and Azerbaijan with Particular Reference to Pre-Islamic Turkic Aspect.PhD diss., Birmingham University

Vale-Taylor, P. (2009). "We will remember them": A mixed- method study to explore which postfuneral remembrance activities are most signi cant and important to bereaved people living with loss, and why those particular activities are chosen. Palliative Medicine, 23, 537-544. istep:

Wolfelt, A. (2014) Understanding Grief: Helping Yourself Heal, Brunner- Routledge, Sussex.

Zamahsari, C. (1947) al-Kassaf. Beyrouth: Dar al-Marifa 